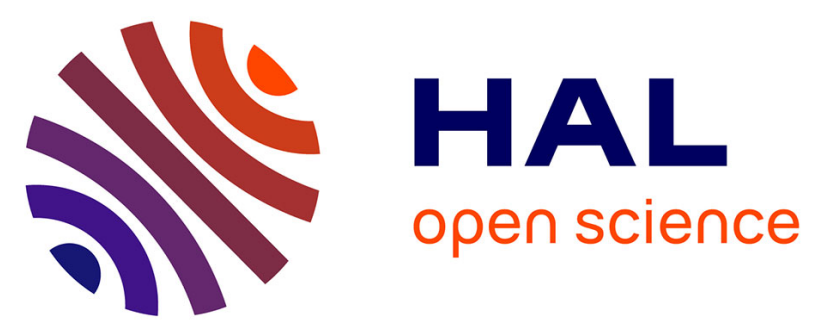

\title{
Extraction of actinides by tertiary amines in room temperature ionic liquids: evidence for anion exchange as a major process at high acidity and impact of acid nature
}

Seraj A Ansari, Prasanta K Mohapatra, Valérie Mazan, Isabelle Billard

\section{To cite this version:}

Seraj A Ansari, Prasanta K Mohapatra, Valérie Mazan, Isabelle Billard. Extraction of actinides by tertiary amines in room temperature ionic liquids: evidence for anion exchange as a major process at high acidity and impact of acid nature. RSC Advances, 2015, 5 (45), pp.35821-35829. 10.1039/c5ra04882f . hal-02271456

\section{HAL Id: hal-02271456 \\ https://hal.science/hal-02271456}

Submitted on 26 Aug 2019

HAL is a multi-disciplinary open access archive for the deposit and dissemination of scientific research documents, whether they are published or not. The documents may come from teaching and research institutions in France or abroad, or from public or private research centers.
L'archive ouverte pluridisciplinaire $\mathbf{H A L}$, est destinée au dépôt et à la diffusion de documents scientifiques de niveau recherche, publiés ou non, émanant des établissements d'enseignement et de recherche français ou étrangers, des laboratoires publics ou privés. 


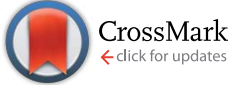

Cite this: RSC Adv., 2015, 5, 35821
Received 19th March 2015 Accepted 13th April 2015

DOI: $10.1039 / c 5 r a 04882 f$

www.rsc.org/advances

\section{Extraction of actinides by tertiary amines in room temperature ionic liquids: evidence for anion exchange as a major process at high acidity and impact of acid nature $\uparrow$}

\begin{abstract}
Seraj A. Ansari, ${ }^{a}$ Prasanta K. Mohapatra, ${ }^{* a}$ Valérie Mazan ${ }^{\mathrm{b}}$ and Isabelle Billard ${ }^{\mathrm{bcd}}$
Extraction of $U(\mathrm{VI})$ and $\mathrm{Pu}(\mathrm{IV})$ using several tri-alkylamines such as tri- $n$-butylamine (TBA), tri- $n$-hexylamine (THA), tri-n-octylamine (TOA), and tri-iso-octylamine (TiOA) in room temperature ionic liquids, $\left[\mathrm{C}_{n}\right.$ mim]$\left[\mathrm{Tf}_{2} \mathrm{~N}\right]$ (where $n=4,6$ or 8 ), was investigated from nitric acid as well as hydrochloric acid medium. In the absence of the amines, the extraction results indicated an increase in the extraction of both $U(\mathrm{VI})$ and $\mathrm{Pu}(\mathrm{IV})$ as a function of the acid concentration which was attributed to the extraction of probable anionic species such as $\mathrm{UO}_{2} \mathrm{X}_{3}{ }^{-}, \mathrm{UO}_{2} \mathrm{X}_{4}{ }^{2-}, \mathrm{PuX}_{5}{ }^{-}$and $\mathrm{PuX}_{6}{ }^{2-}$ (where $\mathrm{X}=\mathrm{Cl}^{-}$or $\mathrm{NO}_{3}{ }^{-}$) according to an anionexchange mechanism involving $\mathrm{Tf}_{2} \mathrm{~N}^{-}$ions. The presence of amines in the ionic liquid enhances the extraction of the metal ions with increased $\mathrm{HCl}$ concentration, especially in the case of $\mathrm{UO}_{2}{ }^{2+}$, but the amines appear to be almost inefficient in $\mathrm{HNO}_{3}$ medium. This is ascribed to the protonation/association of amines via solubilization of $\mathrm{H}^{+}$and $\mathrm{NO}_{3}{ }^{-}$ions in the ionic liquid phase in the case of nitric medium, while hydrochloric acid does not solubilize in ionic liquid, and thus the amine remains efficient. Modeling of the extraction data in $\mathrm{HCl}$ medium for $\mathrm{U}(\mathrm{VI})$ and $\mathrm{Pu}(\mathrm{IV})$ in the presence of amines has been performed and confirmed the anion exchange mechanism.
\end{abstract}

\section{Introduction}

Extraction of actinides from nitric acid feeds has been one of the major challenges and such separation methods find applications in radioactive waste management. Usually, for feeds containing low concentrations of acid (in the $\mathrm{pH}$ range) one employs acidic extractants such as TTA (2-thenoyltrifluoroacetone), HD2EHP (di-2-ethylhexylphosphoric acid), Cyanex 272, etc. while those containing moderate concentrations of nitric acid (i.e., from 1 to $3 \mathrm{M}$ ) require solvating type neutral extractants such as TBP (tri- $n$-butyl phosphate), CMPO (carbamoyl methylene phosphine oxide), TODGA $\left(N, N, N^{\prime}, N^{\prime}\right.$-tetra- $n$ octyldiglycolamide), etc. ${ }^{1-3}$ On the other hand, some radioactive wastes contain actinide ions at rather high concentrations of acid ( $>3 \mathbf{M}$ ) and in such cases amines are usually used as the extractants. ${ }^{1}$

${ }^{a}$ Radiochemistry Division, Bhabha Atomic Research Centre, Trombay, Mumbai-400085, India. E-mail: mpatra@barc.gov.in; Fax: +91-22-25505151

${ }^{b}$ Institut Pluridisciplinaire Hubert Curien, DRS, Radiochemistry Group, CNRS and Strasbourg University, 23 rue du Loess, 67037 Strasbourg Cedex 2, France. E-mail: isabelle.billard@lepme.grenoble-inp.fr

'Univ. Grenoble Alpes, LEPMI, F-38000 Grenoble, France

${ }^{d}$ CNRS, LEPMI, F-38000 Grenoble, France

$\uparrow$ Electronic supplementary information (ESI) available. See DOI: 10.1039/c5ra04882f
Ionic liquids (IL) have gained considerable attention in recent years for metal ion extraction such as actinides/lanthanides ${ }^{3-5}$ and transition elements. ${ }^{6}$ Due to their negligible vapour pressure, non-inflammability and wide liquid range, ILs have been considered as possible 'green' alternatives to conventional molecular diluents. Several important features have been the signature of IL based extraction systems, especially for metal ion extraction which include usually higher extraction and improved separation efficiency as compared to the molecular diluents. $^{3-5}$ As a consequence, ILs have been used for the extraction of actinide ions by many research groups using the above mentioned extractants.

Owing to the growing interest in the recovery of actinides, especially uranium, from various streams including lean solutions and wastes, a large number of publications are available on the recovery of uranium from such feeds using ILs. The extraction of $\mathrm{UO}_{2}{ }^{2+}$ has been investigated in IL using TBP, Cyanex $272,{ }^{9} \mathrm{CMPO}^{\mathbf{1 0}-12}$ TODGA $^{13}$ and malonamides. ${ }^{14}$ Other examples related to either less common actinides and/or ligands, such as amines, can also be found. Zuo et al., ${ }^{15}$ carried out studies on the extraction of $\mathrm{Th}^{4+}$ using a primary amine $\mathrm{N} 1923$ (dialkyl methylamine where the alkyl groups range from $\mathrm{C}_{9} \mathrm{H}_{19}$ to $\left.\mathrm{C}_{11} \mathrm{H}_{23}\right)$ in $\left[\mathrm{C}_{8} \mathrm{mim}\right]\left[\mathrm{PF}_{6}\right]$ which indicated a reverse micellar mechanism and efficient separation of $\mathrm{Th}^{4+}$ from rare earth elements. There are other reports in which ILs containing quaternary ammonium cation such as Aliquat 336 
(A336) have been used for the extraction of metal ions, ${ }^{\mathbf{1 6 , 1 7}}$ including $\mathrm{UO}_{2}{ }^{2+}$ ion extraction. ${ }^{18}$ These studies, however, have not given any information on the mechanism of extraction. Though these extraction systems may not find immediate applications for the separation of actinides in a plant scale, the basic solvent extraction data showed many interesting features making these studies quite relevant.

From this wealth of studies, several drawbacks of the IL based extraction methods have been identified and then have been tentatively fought. For example, ILs with $\mathrm{PF}_{6}{ }^{-}$as the counter anion display large viscosities and show considerable degradation at high concentrations of nitric acid. ${ }^{19}$ These limitations can be easily countered by using ILs containing other favorable counter anions such as $\mathrm{NTf}_{2}{ }^{-}$which have considerably lower viscosities ${ }^{\mathbf{2 0}}$ and are water-stable. Similarly, aqueous solubility of the cationic component of the ILs, which is a consequence of the cation-exchange mechanism acknowledged at low acidities, is more common with ILs containing smaller alkyl groups such as $n$-butyl. The aqueous solubility of the cationic component of ILs can be made insignificant by opting bulkier alkyl groups such as $n$-octyl or $n$-decyl or by use of fluorinated ILs. Unfortunately, with these methods, the overall extraction efficiency is drastically decreased, rending the solution quite inefficient. ${ }^{\mathbf{8} 21}$ Provided the cation exchange mechanism occurring at low acidity is changed to the solvation mechanism at high acidities, performing extraction under high acidic conditions would thus be an elegant way to counter (cationic) pollution of the aqueous phase. However, there is still some debate on the relative importance of anionic exchange and extraction of neutral species at high acidities. ${ }^{22,23}$

Therefore, in the present study, the extraction mechanism of $\mathrm{UO}_{2}{ }^{2+}$ and $\mathrm{Pu}^{4+}$ from acidic feed conditions using several trialkylamines such as tri- $n$-butylamine (TBA), tri- $n$-hexylamine (THA), tri- $n$-octylamine (TOA), and tri-iso-octylamine (TiOA) was investigated in several ILs, $\left[\mathrm{C}_{n} \operatorname{mim}\right]\left[\mathrm{Tf}_{2} \mathrm{~N}\right]$, where $n=4,6$ or 8 . $\mathrm{Pu}^{4+}$ was chosen because there is also a need to understand the extraction behavior of this important actinide ion under moderate to high acidic conditions. This has significant implications in the simultaneous recovery of $\mathrm{U}$ and $\mathrm{Pu}$, including applications in spent nuclear fuel reprocessing. Simulation of the solvent extraction data in the presence of amine was also performed ( $\mathrm{HCl}$ medium) for validation of the extraction mechanism. The simulation results have shown the extraction of negatively charged species through an anion exchange mechanism.

\section{Experimental}

\subsection{Reagents and radiotracers}

Suprapur nitric and hydrochloric acids (Merck) were used for preparing the dilute acid solutions. Ionic liquids (>99\%) were purchased from Iolitec, Germany and were used as received. The trialkylamines (>99\%) were procured from Sigma Aldrich and were used without further purification. All the other reagents were of AR grade.

${ }^{233} \mathrm{U}$, purified from its daughter products following an ion exchange method, ${ }^{24}$ was used as the stock solution. Pu (mainly
${ }^{239} \mathrm{Pu}$ ) was used from the laboratory stocks after confirming its radiochemical purity. The purity of Pu was checked by $\alpha$ spectrometry using a Si-surface barrier detector and also by confirming the absence of ${ }^{241} \mathrm{Am}$ by gamma ray spectrometry. $\mathrm{Pu}^{4+}$ was prepared by addition of a few drops of a dilute $\mathrm{NaNO}_{2}$ solution $(50 \mathrm{mM})$ to a Pu solution taken in $1 \mathrm{M} \mathrm{HNO}_{3}$ which was subsequently extracted using a $0.5 \mathrm{M}$ solution of TTA (2-thenoyltrifluoroacetone) in xylene. The extracted $\mathrm{Pu}^{4+}$ was stripped using $8 \mathrm{M} \mathrm{HNO}_{3}$. The back extracted tracer solution was subsequently washed three times with xylene (to ensure removal of dissolved TTA in the aqueous solution) and was preserved as the stock solution of $\mathrm{Pu}^{4+}$. The stability of the oxidation state was insured due to the strongly complexing medium.

\subsection{Distribution studies}

The amine solutions in ILs were prepared by prolonged ultrasonification which resulted in clear single phase solutions. Leak tight Pyrex tubes with one $\mathrm{mL}$ of the IL phase containing requisite tri-alkylamine was allowed to be vortexed in a thermostated water bath at $25 \pm 0.1{ }^{\circ} \mathrm{C}$ for about an hour with equal volume of the aqueous phase containing the radiotracer in the desired acid concentration. This time was found sufficient to reach the equilibrium condition. The equilibration time was optimized by carrying out extraction kinetics experiments (vide infra). The tubes were subsequently centrifuged for about 5 minutes to enable clear phase separation. After centrifugation, both the phases were separated and assayed radiometrically. ${ }^{239} \mathrm{Pu}$ and ${ }^{233} \mathrm{U}$ were assayed using an alpha liquid scintillation counting system (Hidex, Finland) coupled to a multi-channel analyzer using a toluene-based extractive scintillator cocktail (SRL, Mumbai) containing $0.7 \%(\mathrm{w} / \mathrm{v})$ PPO (2,5-diphenyloxazole), $\quad 0.03 \% \quad(\mathrm{w} / \mathrm{v}) \quad$ POPOP (1,4-di-[2-(5-phenyloxazoyl)]benzene), and 10\% (v/v) HD2EHP (di(2-ethylhexyl) phosphoric acid) which acted as the extractant. The distribution ratio, $D_{\mathrm{M}}$, was defined as the ratio of the activity per unit volume in the organic phase to that in the aqueous phase. Typically, the concentration of $\mathrm{Pu}^{4+}$ was in the range of $10^{-6}-10^{-7} \mathrm{M}$ while that of $\mathrm{UO}_{2}{ }^{2+}$ was in the range of $10^{-5}-10^{-6} \mathrm{M}$. Amines were introduced in the IL phases at $1 \%(\mathrm{v} / \mathrm{v})$. Such a procedure is adopted for the sake of sample preparation convenience, which corresponded to $42.0 \mathrm{mM}$ TBA, $29.6 \mathrm{mM}$ THA, $22.9 \mathrm{mM}$ TOA and $23.1 \mathrm{mM}$ TiOA. All the extraction experiments were carried out in duplicate with a precision of $\pm 5 \%$ of standard deviation.

\subsection{Acid uptake}

Acid uptake in the IL phase (in the absence and in the presence of amines) was determined in the range 1-6 $\mathrm{M}$ of initial acid concentration by titration of the aqueous phase after equilibration with the respective IL phases. The IL phases were first equilibrated with aqueous phase containing required acid, followed by contacting the IL phase with deionized water $(\mathrm{pH} 7)$. Subsequently, this back extracted acid was titrated using phenolphthalein indicator with standard $\mathrm{NaOH}$ solution. Uncertainties in the $\mathrm{H}^{+}$titrations were within 5\% (no amine) or $10 \%$ (with amine). All experiments have been performed at room temperature. 


\subsection{Measurements of $\mathrm{C}_{8} \mathrm{mim}^{+}$and $\mathrm{Tf}_{2} \mathrm{~N}^{-}$solubilities}

Ion concentrations in the aqueous phase have been measured by NMR, so in this case only, deuterated water (99\%) and deuterated hydrochloric acid, DCl, (analytical grade, Sigma Aldrich) have been used. Equal volumes of the acidic aqueous phase and of the pure IL phase (no ligand added) have been contacted in a mechanical shaker for three hours. Then, phases have been separated by centrifugation and aliquots of the aqueous equilibrated phase have been measured by NMR. The standard used in ${ }^{1} \mathrm{H}$-NMR was dihydrated sodium citrate $\mathrm{C}_{6} \mathrm{H}_{5} \mathrm{Na}_{3} \mathrm{O}_{7} \cdot 2 \mathrm{H}_{2} \mathrm{O}$ (Merck, $>98 \%$ ), for IL cation determination. The standard used in ${ }^{19} \mathrm{~F}-\mathrm{NMR}$ was sodium trifluoroacetate (Alfa Aesar, $>98 \%$ purity), for $\mathrm{Tf}_{2} \mathrm{~N}^{-}$determination. The NMR protocol is identical to that detailed elsewhere. ${ }^{25}$ Data are presented as supplementary materials (ESI $\dagger$ ).

\section{Results and discussion}

\subsection{Acid uptakes and amine protonation in ionic liquids}

Acid uptake by the organic phase is one of the key features of extraction, as this may impact both the aqueous speciation and the possibilities of ion exchange. Although many ILs are hydrophobic enough to generate biphasic systems when contacted with acidic aqueous solutions, they are known to accept rather high water and acid contents in their bulk. For example, $\mathrm{HNO}_{3}$ enters the $\left[\mathrm{C}_{4} \mathrm{mim}\right]\left[\mathrm{Tf}_{2} \mathrm{~N}\right]$ phase up to $c a .6 \%$, in the range of initial acidic concentration 1-6 M..$^{25,26}$ By contrast, $\mathrm{HCl}$ does not solubilize in $\left[\mathrm{C}_{4} \mathrm{mim}\right]\left[\mathrm{Tf}_{2} \mathrm{~N}\right]$, with acid uptake below the titration uncertainty. ${ }^{25,26}$ Therefore, acid uptakes by the pure IL phases (no ligand, no metal ion) have been measured as a function of acid nature $\left(\mathrm{HNO}_{3}, \mathrm{HCl}\right)$ and acid concentration. Typical results for $\left[\mathrm{C}_{8} \mathrm{mim}\right]\left[\mathrm{Tf}_{2} \mathrm{~N}\right](\mathrm{HCl})$ are shown in Fig. 1.

In the three ILs investigated, it is observed that $\mathrm{HCl}$ solubilization is negligible, while $\mathrm{HNO}_{3}$ solubilization is significant,

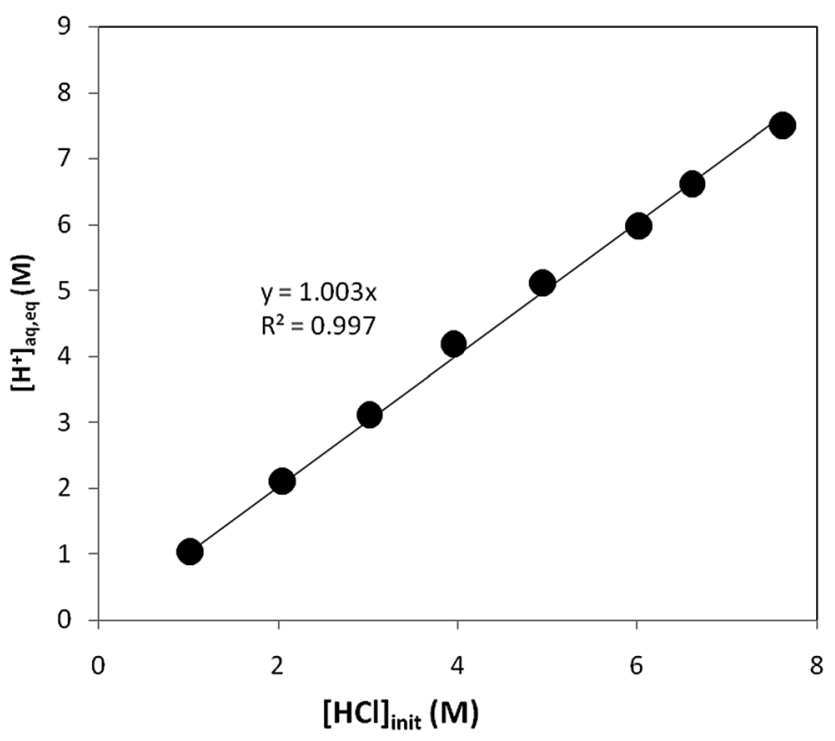

Fig. $1 \mathrm{H}^{+}$equilibrium value in the aqueous phase, $\left[\mathrm{H}^{+}\right]_{\text {aq,eq }}$ as a function of initial $\mathrm{HCl}$ value for $\left[\mathrm{C}_{8} \mathrm{mim}\right]\left[\mathrm{Tf}_{2} \mathrm{~N}\right]$. Solid line: linear fit. as about $5-6 \% \mathrm{HNO}_{3}$ is extracted into the IL phase $(n=4$ and $n=10) .{ }^{25}$ The acid extraction data was also determined in the presence of amines, but the data was similar to pure IL phase within the measured uncertainty due to low amine concentrations used. The solubilization data indicate that the amines/IL solution contacted with $\mathrm{HCl}$ solution may behave differently than those with $\mathrm{HNO}_{3}$. This property has significant effect on the extraction of $\mathrm{UO}_{2}{ }^{2+}$ and $\mathrm{Pu}^{4+}$ by these amines, and will be discussed in the following sections.

\subsection{Extraction of actinides in the absence of amines}

We now turn to extraction of metallic ions, as a function of acid nature and amount. The distribution ratio $(D)$ values were measured as a function of $\mathrm{HNO}_{3}$ and $\mathrm{HCl}$ concentrations in the absence of amines and the results are listed in Table 1. As a typical example, $D$ values for $\mathrm{UO}_{2}{ }^{2+}$ and $\mathrm{Pu}^{4+}$ from $\mathrm{HNO}_{3} / \mathrm{H}_{2} \mathrm{O}$ towards pure $\left[\mathrm{C}_{8} \mathrm{mim}\right]\left[\mathrm{Tf}_{2} \mathrm{~N}\right]$ (in the absence of ligand) are shown in Fig. 2. The extraction of $\mathrm{UO}_{2}{ }^{2+}$ is insignificant in the acid range from 1-6 $\mathrm{M} \mathrm{HNO}_{3}$. On the other hand, extraction of $\mathrm{Pu}^{4+}$ increases with $\mathrm{HNO}_{3}$ concentration. Close examination of the data of Table 1 lead to the following comments. Even at high acid concentration $\left(\mathrm{HCl}\right.$ or $\left.\mathrm{HNO}_{3}\right)$ and whatever the IL used, $\mathrm{UO}_{2}{ }^{2+}$ extraction is always below 0.1 and can be considered as not negligible only at $6 \mathrm{M}$ acidities $(D>0.1)$. For $\mathrm{UO}_{2}{ }^{2+}$ extraction, no real difference can be detected between $\mathrm{HNO}_{3}$ and $\mathrm{HCl}$, and no significant difference is observed from one IL to the other, which may be ascribed, in part, to the rather low $D$ values measured. By contrast, $\mathrm{Pu}^{4+}$ extraction from nitric acid medium is efficient, with all values above 1 and up to 3 at $\left[\mathrm{HNO}_{3}\right]=6 \mathrm{M}$, while $\mathrm{HCl}$ leads to lower $\mathrm{Pu}^{4+}$ distribution ratios, ranging from $<0.1$ to 0.8 at $[\mathrm{HCl}]=6 \mathrm{M}$.

Though the extraction of $\mathrm{UO}_{2}{ }^{2+}$ and $\mathrm{Pu}^{4+}$ from $\mathrm{HCl}$ medium (in the absence of any extractant) is reported here for the first time, their extraction from $\mathrm{HNO}_{3}$ medium has been reported by several research groups. In the case of $\mathrm{UO}_{2}{ }^{2+}$, our value $D_{\mathrm{U}(\mathrm{VI})}=$ 0.184 in $\left[\mathrm{C}_{8} \mathrm{mim}\right]\left[\mathrm{Tf}_{2} \mathrm{~N}\right],\left[\mathrm{HNO}_{3}\right]=6 \mathrm{M}$ is in line with data collected at $\left[\mathrm{HNO}_{3}\right]=5 \mathrm{M}$ in $\left[\mathrm{C}_{8} \mathrm{mim}\right]\left[\mathrm{Tf}_{2} \mathrm{~N}\right]\left(D_{\mathrm{U}(\mathrm{VI})}=0.135\right) .{ }^{27}$ Similarly, $D_{\mathrm{Pu}(\mathrm{IV})}$ values equal to $1.6\left(\left[\mathrm{C}_{4} \mathrm{mim}\right]\left[\mathrm{PF}_{6}\right],\left[\mathrm{HNO}_{3}\right]=5\right.$ $\mathrm{M})^{28}$ or $7.8\left(\left[\mathrm{C}_{8} \mathrm{mim}\right]\left[\mathrm{PF}_{6}\right],\left[\mathrm{HNO}_{3}\right]=5 \mathrm{M}\right),{ }^{29}$ have been obtained. Although these data are based on slightly different ILs and chemical conditions, they are in line with our measurements. By contrast to this work, Rout et al. ${ }^{30}$ reported higher extraction of $\mathrm{Pu}^{4+}$ by $\left[\mathrm{C}_{n} \mathrm{mim}\right]\left[\mathrm{Tf}_{2} \mathrm{~N}\right]$ from 1-5 $\mathrm{M} \mathrm{HNO}_{3}$ with $D_{\mathrm{Pu}(\mathrm{IV})}$ values equal to $6.6(n=4)$ and $37.5(n=8)$. On the other hand, Patil et $a l .{ }^{31}$ reported the extraction of the $\mathrm{Pu}$ metal ion to a much lower extent for the same chemical conditions, but in line with the data obtained in the present work. Relatively large $D_{\mathrm{Pu}(\mathrm{IV})}$ values reported by Rout et $a .^{28,30}$ could be attributed partly to liquid scintillation counting errors, particularly relevant at higher acidities, which are due to quenching in case of dioxane based scintillator cocktail or inefficient extraction in case of an extractive scintillator cocktail. It may be noted that the toluene based extractive scintillator cocktail requires the addition of a particular amount of a complexing agent such as di-2ethylhexylphosphoric acid. 
Table 1 Distribution of $\mathrm{UO}_{2}{ }^{2+}$ and $\mathrm{Pu}^{4+}$ from varying concentrations of acid in the absence of amines

\begin{tabular}{|c|c|c|c|c|c|c|c|c|c|c|c|c|}
\hline \multirow[b]{3}{*}{ [Acid], M } & \multicolumn{6}{|c|}{ Distribution ratio of $\mathrm{UO}_{2}{ }^{2+}$} & \multicolumn{6}{|c|}{ Distribution ratio of $\mathrm{Pu}^{4+}$} \\
\hline & \multicolumn{2}{|c|}{$\underline{\left[\mathrm{C}_{4} \operatorname{mim}\right]\left[\mathrm{Tf}_{2} \mathrm{~N}\right]}$} & \multicolumn{2}{|c|}{$\underline{\left[\mathrm{C}_{6} \mathrm{mim}\right]\left[\mathrm{Tf}_{2} \mathrm{~N}\right]}$} & \multicolumn{2}{|c|}{$\underline{\left[\mathrm{C}_{8} \mathrm{mim}\right]\left[\mathrm{Tf}_{2} \mathrm{~N}\right]}$} & \multicolumn{2}{|c|}{$\underline{\left[\mathrm{C}_{4} \operatorname{mim}\right]\left[\mathrm{Tf}_{2} \mathrm{~N}\right]}$} & \multicolumn{2}{|c|}{$\underline{\left[\mathrm{C}_{6} \mathrm{mim}\right]\left[\mathrm{Tf}_{2} \mathrm{~N}\right]}$} & \multicolumn{2}{|c|}{$\underline{\left[\mathrm{C}_{8} \mathrm{mim}\right]\left[\mathrm{Tf}_{2} \mathrm{~N}\right]}$} \\
\hline & $\mathrm{HNO}_{3}$ & $\mathrm{HCl}$ & $\mathrm{HNO}_{3}$ & $\mathrm{HCl}$ & $\mathrm{HNO}_{3}$ & $\mathrm{HCl}$ & $\mathrm{HNO}_{3}$ & $\mathrm{HCl}$ & $\mathrm{HNO}_{3}$ & $\mathrm{HCl}$ & $\mathrm{HNO}_{3}$ & $\mathrm{HCl}$ \\
\hline 1 & 0.001 & 0.002 & 0.001 & 0.001 & 0.001 & 0.001 & 0.004 & 0.009 & 0.014 & 0.010 & 0.020 & 0.016 \\
\hline 3 & 0.008 & 0.001 & 0.011 & 0.002 & 0.012 & 0.003 & 0.396 & 0.004 & 1.06 & 0.004 & 1.28 & 0.006 \\
\hline 4 & 0.026 & 0.004 & 0.034 & 0.009 & 0.041 & 0.017 & 1.30 & 0.008 & 2.02 & 0.010 & 2.31 & 0.011 \\
\hline 6 & 0.136 & 0.060 & 0.179 & 0.153 & 0.184 & 0.418 & 2.70 & 0.148 & 2.93 & 0.380 & 3.00 & 0.807 \\
\hline
\end{tabular}

In order to understand our extraction data, it has to be recalled that actinide ions such as $\mathrm{UO}_{2}{ }^{2+}$ and $\mathrm{Pu}^{4+}$ form anionic species in $\mathrm{HCl}$ medium (for example, $\mathrm{UO}_{2} \mathrm{Cl}_{3}{ }^{-}, \mathrm{UO}_{2} \mathrm{Cl}_{4}{ }^{2-}$, $\mathrm{PuCl}_{5}{ }^{-}, \mathrm{PuCl}_{6}{ }^{2-}$ ) as well as $\mathrm{HNO}_{3}$ medium (for example, $\mathrm{Pu}\left(\mathrm{NO}_{3}\right)_{5}{ }^{-}$and $\left.\mathrm{Pu}\left(\mathrm{NO}_{3}\right)_{6}{ }^{2-}\right)$ at moderate to high concentrations of the acids. ${ }^{27}$ In ionic liquid medium where the diluent itself is constituted of a cation and an anion, such anionic complexes can be partitioned even in the absence of the extractant molecules, according to:

$$
\mathrm{MX}_{i \mathrm{aq}}{ }^{m-}+j \mathrm{Tf}_{2} \mathrm{~N}_{\mathrm{IL}}{ }^{-} \rightleftharpoons \mathrm{MX}_{i \mathrm{IL}}{ }^{m-}+j \mathrm{Tf}_{2} \mathrm{~N}_{\mathrm{aq}}{ }^{-}
$$

The extraction mechanism above is of the anion-exchange type and has been observed in some systems ${ }^{\mathbf{1 4 3 2}}$ but not so well-documented, particularly in the case of actinides. In order to validate the general extraction mechanism as in eqn (1), experiments were carried out as a function of $\operatorname{LiNTf}_{2}$ concentration in the aqueous phase at a fixed acid concentration. As expected, the addition of $\mathrm{NTf}_{2}{ }^{-}$in to the aqueous phase suppresses the metal ion extraction, supporting eqn (1) as the appropriate extraction mechanism. Slopes of the plots of $\log D_{\mathrm{M}}$ vs. $\log \left[\mathrm{Tf}_{2} \mathrm{~N}^{-}\right]$for $\mathrm{UO}_{2}{ }^{2+}$ extraction from $6 \mathrm{M} \mathrm{HCl}$ and $\mathrm{Pu}^{4+}$ extraction from $6 \mathrm{M} \mathrm{HNO}_{3}$ were found to be close to -2 (Fig. 3),

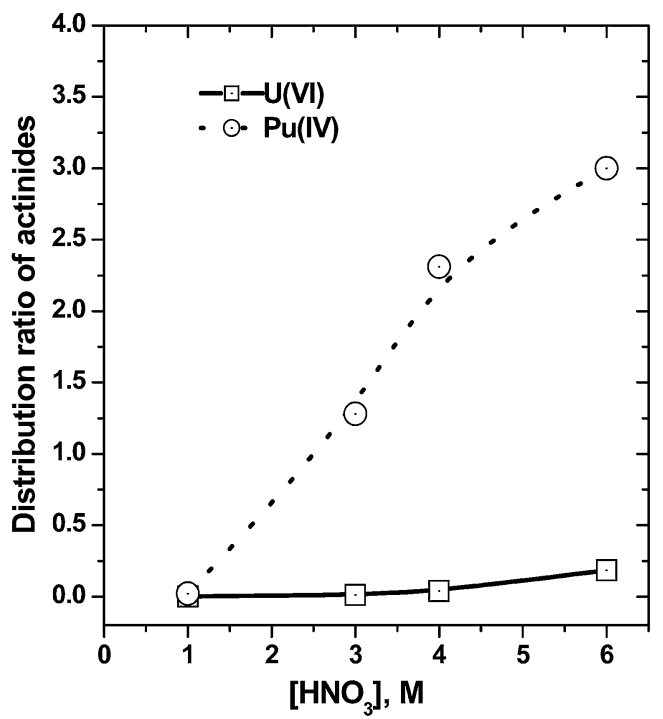

Fig. 2 Extraction of actinides by $\mathrm{C}_{8} \mathrm{mim} \cdot \mathrm{Tf}_{2} \mathrm{~N}$ (in the absence of ligand). Solid lines are guide for the eye only. suggesting extraction of $\left[\mathrm{UO}_{2} \mathrm{Cl}_{4}\right]^{2-}$ and $\left[\mathrm{Pu}\left(\mathrm{NO}_{3}\right)_{6}\right]^{2-}$ as per the following equations:

$$
\begin{gathered}
\mathrm{UO}_{2} \mathrm{Cl}_{4 \mathrm{aq}}{ }^{2-}+2 \mathrm{Tf}_{2} \mathrm{~N}_{\mathrm{IL}}{ }^{-} \rightleftharpoons \mathrm{UO}_{2} \mathrm{Cl}_{4 \mathrm{IL}}{ }^{2-}+2 \mathrm{Tf}_{2} \mathrm{~N}_{\mathrm{aq}}{ }^{-} \\
\mathrm{Pu}\left(\mathrm{NO}_{3}\right)_{6 \mathrm{aq}}{ }^{2-}+2 \mathrm{Tf}_{2} \mathrm{~N}_{\mathrm{IL}}{ }^{-} \rightleftharpoons \mathrm{Pu}\left(\mathrm{NO}_{3}\right)_{6 \mathrm{IL}}{ }^{2-}+2 \mathrm{Tf}_{2} \mathrm{~N}_{\mathrm{aq}}{ }^{-}
\end{gathered}
$$

\subsection{Extraction of actinides in the presence of amines}

It is well-known that the anionic species involved in eqn (2) and (3) above are not favorably extracted towards pure molecular solvents, because they only accept neutral species in their bulk. Therefore, an extracting agent is required in order to extract these metal ions through neutral complexes. When using IL, as shown in the above section, extraction occurs even in the absence of extractant, but in the systems under investigation in this work, the distribution ratio are nonetheless rather low. We, therefore, considered amines as possible extracting agents. The extraction data of $\mathrm{UO}_{2}{ }^{2+}$ from $\mathrm{HCl}$ medium by the four amine ligands dissolved in ILs were measured and data obtained for 6 M HCl are summarized in Table 2. Comparison with data displayed in Table 1 shows that addition of any of the amines is beneficial to uranium extraction, with $D_{\mathrm{U}(\mathrm{VI})}$ values in the

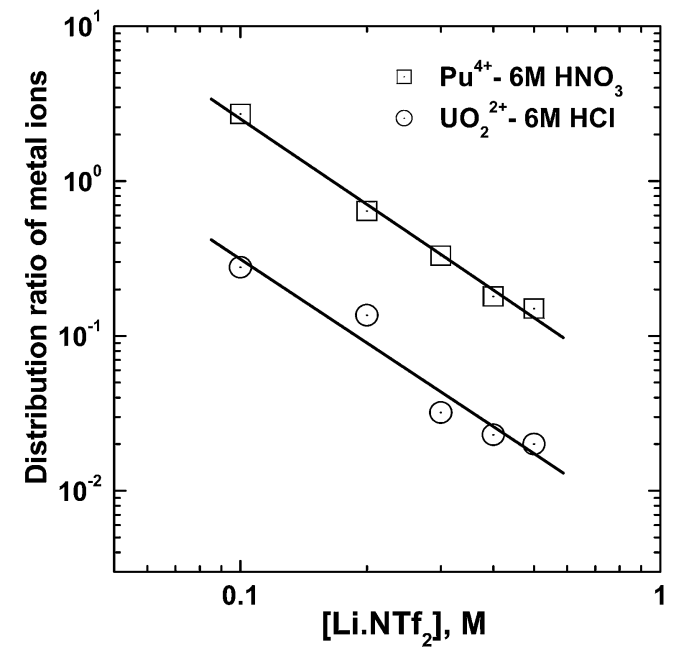

Fig. 3 Distribution ratio of actinide ions by pure $\left[\mathrm{C}_{8} \operatorname{mim}\right]\left[\mathrm{Tf}_{2} \mathrm{~N}\right]$ in the presence of varying concentration of $\mathrm{Li} \cdot \mathrm{NTf}_{2}$ salt; $\mathrm{Pu}^{4+}$ slope: $-1.83 \pm$ $0.09 ; \mathrm{UO}_{2}^{2+}$ slope: $-1.79 \pm 0.25$. 
Table 2 Distribution of $\mathrm{UO}_{2}{ }^{2+}$ by amines/ILs; aqueous phase: $6 \mathrm{M} \mathrm{HCl}$; organic phase: $42 \mathrm{mM}$ tri- $n$-butylamine, $30 \mathrm{mM}$ tri- $n$-hexyl amine, 23 $\mathrm{mM}$ tri-n-octyl amine and $23 \mathrm{mM}$ tri-iso-octyl amine

\begin{tabular}{|c|c|c|c|}
\hline Amine & RTIL & $D_{\mathrm{U}(\mathrm{VI})}$ & $D_{\mathrm{Pu}(\mathrm{IV})}$ \\
\hline \multirow[t]{3}{*}{ Tri- $n$-butyl amine } & {$\left[\mathrm{C}_{4} \mathrm{mim}\right]\left[\mathrm{NTf}_{2}\right]$} & 0.09 & \\
\hline & {$\left[\mathrm{C}_{6} \mathrm{mim}\right]\left[\mathrm{NTf}_{2}\right]$} & 0.57 & \\
\hline & {$\left[\mathrm{C}_{8} \mathrm{mim}\right]\left[\mathrm{NTf}_{2}\right]$} & 6.50 & 5.38 \\
\hline \multirow[t]{3}{*}{ Tri- $n$-hexyl amine } & {$\left[\mathrm{C}_{4} \mathrm{mim}\right]\left[\mathrm{NTf}_{2}\right]$} & 0.09 & \\
\hline & {$\left[\mathrm{C}_{6} \mathrm{mim}\right]\left[\mathrm{NTf}_{2}\right]$} & 0.40 & \\
\hline & {$\left[\mathrm{C}_{8} \mathrm{mim}\right]\left[\mathrm{NTf}_{2}\right]$} & 4.29 & 3.34 \\
\hline \multirow[t]{3}{*}{ Tri- $n$-octyl amine } & {$\left[\mathrm{C}_{4} \mathrm{mim}\right]\left[\mathrm{NTf}_{2}\right]$} & 0.08 & \\
\hline & {$\left[\mathrm{C}_{6} \mathrm{mim}\right]\left[\mathrm{NTf}_{2}\right]$} & 0.31 & \\
\hline & {$\left[\mathrm{C}_{8} \mathrm{mim}\right]\left[\mathrm{NTf}_{2}\right]$} & 2.56 & 1.94 \\
\hline \multirow[t]{3}{*}{ Tri-iso-octyl amine } & {$\left[\mathrm{C}_{4} \mathrm{mim}\right]\left[\mathrm{NTf}_{2}\right]$} & 0.08 & \\
\hline & {$\left[\mathrm{C}_{6} \mathrm{mim}\right]\left[\mathrm{NTf}_{2}\right]$} & 0.32 & \\
\hline & {$\left[\mathrm{C}_{8} \mathrm{mim}\right]\left[\mathrm{NTf}_{2}\right]$} & 3.26 & 2.07 \\
\hline
\end{tabular}

presence of amine always larger than in its absence. This conclusion also applies for $\mathrm{Pu}^{4+}$ extraction. However, differences are small in some cases and extraction of $\mathrm{UO}_{2}{ }^{2+}$ from $6 \mathrm{M}$ $\mathrm{HCl}$ increases with increase in the alkyl chain length of the IL $\left(\left[\mathrm{C}_{n} \mathrm{mim}\right]\left[\mathrm{Tf}_{2} \mathrm{~N}\right]\right)$ from butyl to hexyl with all the four amines (Fig. 4). For subsequent studies, only $\left[\mathrm{C}_{8} \mathrm{mim}\right]\left[\mathrm{Tf}_{2} \mathrm{~N}\right]$ was employed as it gives superior distribution values.

The kinetics for the extraction of $\mathrm{UO}_{2}{ }^{2+}$ by amines (TBA, THA and TOA) dissolved in $\left[\mathrm{C}_{8} \mathrm{mim}\right]\left[\mathrm{Tf}_{2} \mathrm{~N}\right]$ was investigated and the results are shown in Fig. 5. Results reveal that the extraction equilibria are reached within $15 \mathrm{~min}$ of equilibration for all the three amines. It should be noted that the distribution behavior and kinetics for extraction with TiOA was similar to that of TOA. As reported in several studies involving the ILs, relatively slower extraction kinetics is attributed to the higher viscosity of the ILs as compared to molecular diluents ${ }^{22}$ although chemical effects

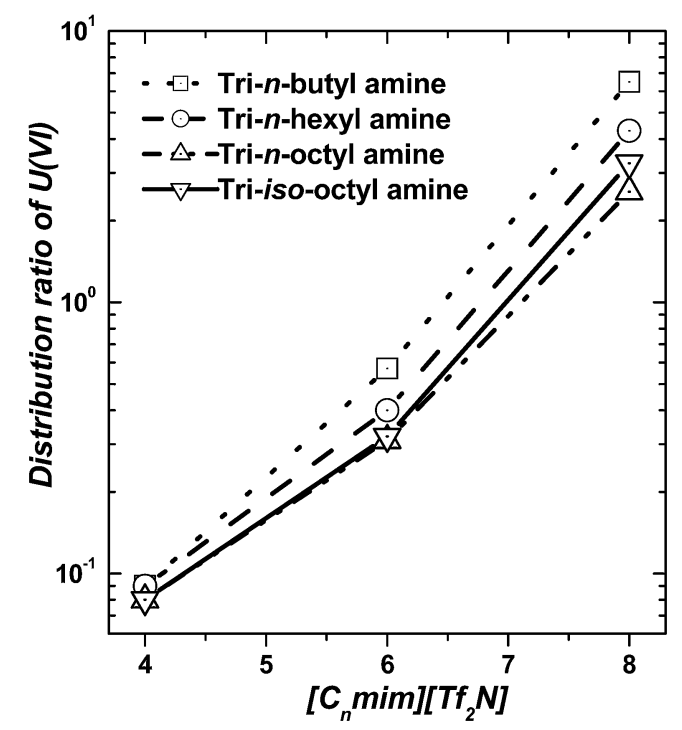

Fig. 4 Effect of alkyl group of $\left[\mathrm{C}_{n}\right.$ mim] $\left[\mathrm{Tf}_{2} \mathrm{~N}\right]$ on extraction of $\mathrm{UO}_{2}{ }^{2+}$. Aqueous phase: $6 \mathrm{M} \mathrm{HCl}$; organic phase: $1 \% \mathrm{v} / \mathrm{v}$ of the tertiary amine in RTIL. Solid lines are guide for the eye only.

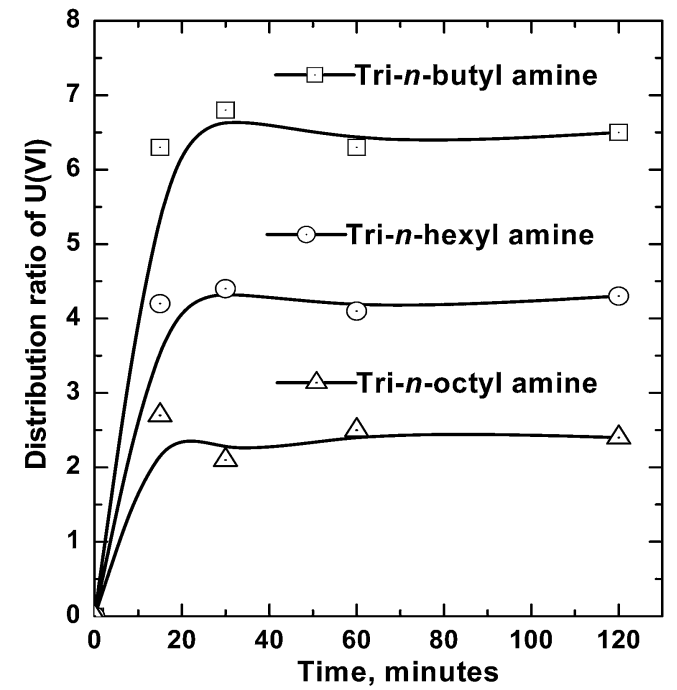

Fig. 5 Distribution ratio of $\mathrm{UO}_{2}{ }^{2+}$ as a function of time. Ligand: $1 \% \mathrm{v} / \mathrm{v}$ tertiary amine/[C $\left.\mathrm{C}_{8} \operatorname{mim}\right]\left[\mathrm{Tf}_{2} \mathrm{~N}\right]$; aqueous phase: $6 \mathrm{M} \mathrm{HCl}$.

have been evidenced in some cases. ${ }^{33}$ Though the kinetics studies were performed with all the four amines, for simplicity of the system in the present work, we focused rest of the study with TBA in $\left[\mathrm{C}_{8} \mathrm{mim}\right]\left[\mathrm{Tf}_{2} \mathrm{~N}\right]$.

Effect of $\mathrm{HCl}$ concentration on $\mathrm{UO}_{2}{ }^{2+}$ and $\mathrm{Pu}^{4+}$ extraction was investigated and the results are shown in Fig. 6 . The $D$ value for $\mathrm{UO}_{2}{ }^{2+}$ increases sharply after $3 \mathrm{M} \mathrm{HCl}$. Increase in $\mathrm{Pu}^{4+}$ extraction is also pronounced above $3 \mathrm{M} \mathrm{HCl}$. These distribution values should be ascribed, for the main part, to the presence of TBA, although the pure IL also contributes to the metal extraction as discussed above. In particular, $D_{\mathrm{U}(\mathrm{VI})}$ is equal to 6.5 at the highest $\mathrm{HCl}$ concentration used in this work in the presence of TBA, to be compared to $D_{\mathrm{U}(\mathrm{VI})}=0.42$ without it. Similarly, $D_{\mathrm{Pu}(\mathrm{IV})}$ values amount to 5.38 and 0.81 with and without TBA, respectively $([\mathrm{HCl}]=6 \mathrm{M})$. This contribution of the

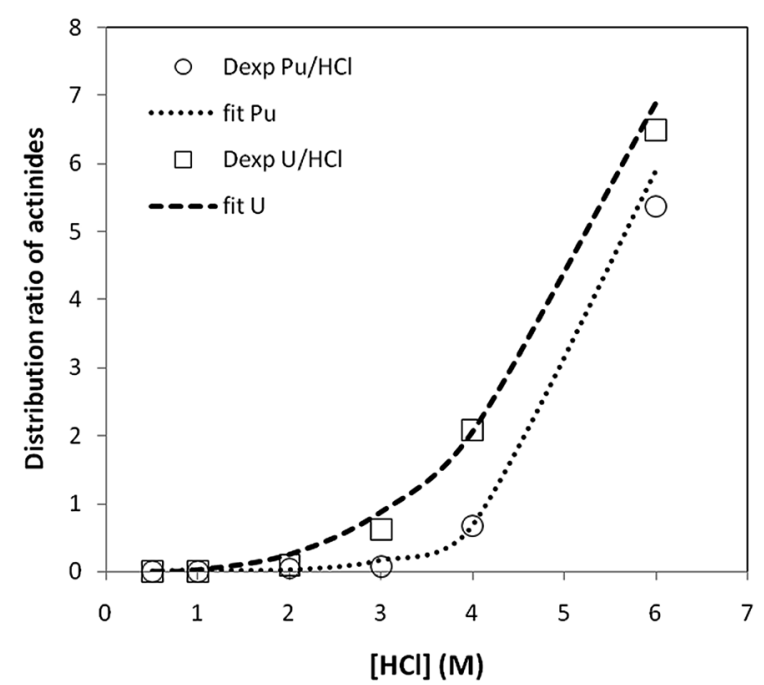

Fig. 6 Distribution behaviour of $\mathrm{UO}_{2}{ }^{2+}$ and $\mathrm{Pu}^{4+}$ in $\mathrm{HCl}$ medium by tri$n$-butylamine/[C $\left.\mathrm{C}_{8} \mathrm{mim}\right]\left[\mathrm{Tf}_{2} \mathrm{~N}\right]$. [Amine]: $1 \% \mathrm{v} / \mathrm{v}\left(42 \mathrm{mmol} \mathrm{L}^{-1}\right)$. 
ligand is also confirmed by the experiments performed at a fixed acidity (6 M HCl) and variable ligand concentration (Fig. 7), where the distribution ratio for $\mathrm{UO}_{2}{ }^{2+}$ and $\mathrm{Pu}^{4+}$ in the absence of amine have been plotted for comparison purposes. By contrast, extraction data in $\mathrm{HNO}_{3}$ medium evidence a rather limited effect of TBA : $D_{\mathrm{U}(\mathrm{VI})}=0.28$ and 0.18 with and without the ligand respectively, for $6 \mathrm{M} \mathrm{HNO}_{3}\left(D_{\mathrm{Pu}(\mathrm{IV})}=3.39\right.$ and 3.00, same chemical conditions). This demonstrates that the nature of the acid is a key to the extraction efficiency by the TBA. The most obvious difference between $\mathrm{HNO}_{3}$ and $\mathrm{HCl}$ media is the amount of $\mathrm{H}^{+}$dissolving in the IL phase, from $0 \%$ ( $\mathrm{HCl}$ ) (this work) to about $6 \%\left(\mathrm{HNO}_{3}\right) \cdot{ }^{25}$ However, this difference in $\mathrm{H}^{+}$ values induces other differences that we suspect to be the rationale for the observed change in extraction efficiencies between $\mathrm{HCl}$ and $\mathrm{HNO}_{3}$ media. In the case of $\mathrm{HCl}$ media (ESI + ), the equilibrium concentrations of $\mathrm{C}_{8} \mathrm{mim}^{+}$and $\mathrm{Tf}_{2} \mathrm{~N}^{-}$ ions in the aqueous phase are very low. Also, the difference between the two amounts only to a few mM: a value an order of magnitude smaller than the amine concentration used in this work. Consequently, this implies that $\mathrm{Cl}^{-}$ions do not transfer significantly to the IL phase either. By contrast, it has been shown previously that in $\mathrm{HNO}_{3}$ media and $\left[\mathrm{C}_{4} \mathrm{mim}\right]\left[\mathrm{Tf}_{2} \mathrm{~N}\right]$ or $\left[\mathrm{C}_{10} \mathrm{mim}\right]\left[\mathrm{Tf}_{2} \mathrm{~N}\right]$, solubilization of the $\mathrm{Tf}_{2} \mathrm{~N}^{-}$ions in the aqueous phase is more important, in the range of $100(n=4)$ to $50 \mathrm{mM}(n=10)$, while the $\mathrm{C}_{4} \mathrm{mim}^{+}$or $\mathrm{C}_{10} \mathrm{mim}^{+}$solubilities are at least $20 \mathrm{mM}$ lower than that of $\mathrm{Tf}_{2} \mathrm{~N}^{-}$. Interpolation of these data for $n=8$ implies a transfer of $\mathrm{NO}_{3}{ }^{-}$ions to the IL phase, in amounts of the order the $\mathrm{H}^{+}$transfer (5-6\%), which is above the amine amount. In addition, $\mathrm{HNO}_{3}$ is known to associate significantly above $3 \mathrm{M},{ }^{34}$ which would also allow

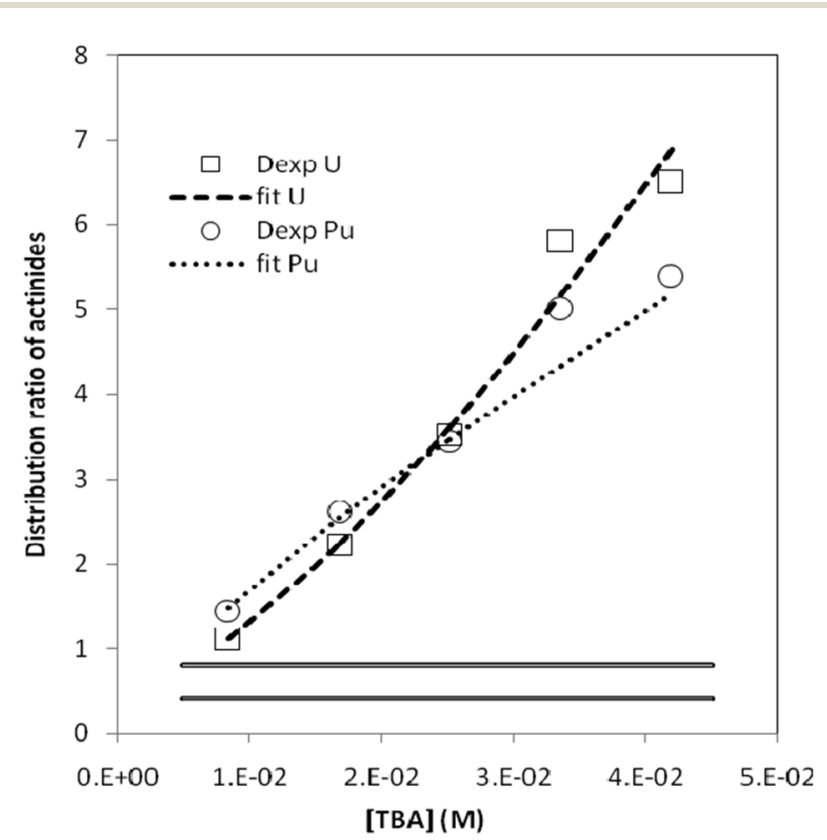

Fig. 7 Ligand variation studies to determine stoichiometry of the extracted species. Aqueous phase: $6 \mathrm{M} \mathrm{HCl}$; organic phase: tri- $n$ butylamine/[ $\left.\mathrm{C}_{8} \mathrm{mim}\right]\left[\mathrm{Tf}_{2} \mathrm{~N}\right]$; experimental data: $\mathrm{Pu}^{4+}$ slope: $-1.25 \pm 0.08$; $\mathrm{UO}_{2}{ }^{2+}$ slope: $-1.39 \pm 0.11$. Upper horizontal line: $D_{U(\mathrm{VI})}$ in the absence of amine; lower horizontal line: $D_{\mathrm{Pu}(\mathrm{IV})}$ in the absence of amine. transfer of $\mathrm{HNO}_{3}$ neutral entities to the IL phase. During extraction, whatever the acid used, plenty of $\mathrm{H}^{+}$ions may interact with the amine to form a protonated amine, $\mathrm{R}_{3} \mathrm{NH}^{+}$, which is the potential extracting agent for $\mathrm{U}(\mathrm{vI})$ and $\mathrm{Pu}(\mathrm{Iv})$. However, in $\mathrm{HNO}_{3}$ media, the competition with amine- $\mathrm{HNO}_{3}$ association in the IL phase renders the amine moiety inefficient, thus leading to a difference in the metal ion extraction between $\mathrm{HCl}$ and $\mathrm{HNO}_{3}$ media. In other words, solubilization of $\sim 5-6 \% \mathrm{HNO}_{3}$ is sufficient to react with $1 \%$ amines, and therefore, amines are not free to participate in extraction of actinides.

Ligand stoichiometry of the extracted species was determined for both $\mathrm{UO}_{2}{ }^{2+}$ and $\mathrm{Pu}^{4+}$ from $6 \mathrm{M} \mathrm{HCl}$ by slope analysis (Fig. 7). The corrections in the distribution ratios were made by subtracting the $D_{\mathrm{M}}$ values of $\mathrm{UO}_{2}{ }^{2+}$ and $\mathrm{Pu}^{4+}$ by the pure IL at 6 $\mathrm{M} \mathrm{HCl}$. Results indicated the extraction of predominantly $1: 1$ (metal to ligand) species. This suggests that the extracted species contain one amine molecule. Furthermore, the dependence of $\mathrm{UO}_{2}{ }^{2+}$ and $\mathrm{Pu}^{4+}$ extraction as a function of $\mathrm{Tf}_{2} \mathrm{~N}^{-}$added concentration in the aqueous phase (Fig. 8) was found closer to 1 than 2 as indicated in the absence of the amines (vide supra). These results confirm the following extraction equilibria, involving one amine (as discussed above) and either one or two IL anions, depending on the charge of the envisioned extracted species: $K_{\mathrm{Pu} 5}$

$$
\begin{aligned}
\mathrm{PuCl}_{5 \mathrm{aq}}{ }^{-}+\mathrm{R}_{3} \mathrm{NH}_{\mathrm{IL}}{ }^{+}+\mathrm{Tf}_{2} \mathrm{~N}_{\mathrm{IL}}{ }^{-} \stackrel{K_{\mathrm{Pu} 5}}{\rightleftharpoons} \\
{\left[\mathrm{R}_{3} \mathrm{NH} \cdot \mathrm{PuCl}_{5}\right]_{\mathrm{IL}}+\mathrm{Tf}_{2} \mathrm{~N}_{\mathrm{aq}}{ }^{-} }
\end{aligned}
$$

$\mathrm{UO}_{2} \mathrm{Cl}_{3 \mathrm{aq}}{ }^{-}+\mathrm{R}_{3} \mathrm{NH}_{\mathrm{IL}}{ }^{+}+\mathrm{Tf}_{2} \mathrm{~N}_{\mathrm{IL}}{ }^{-} \stackrel{K_{\mathrm{U} 3}}{=}$

$$
\left[\mathrm{R}_{3} \mathrm{NH} \cdot \mathrm{UO}_{2} \mathrm{Cl}_{3}\right]_{\mathrm{IL}}+\mathrm{Tf}_{2} \mathrm{~N}_{\mathrm{aq}}{ }^{-}
$$

$$
\begin{aligned}
\mathrm{PuCl}_{6 \mathrm{aq}}{ }^{2-}+\mathrm{R}_{3} \mathrm{NH}_{\mathrm{IL}}{ }^{+}+2 \mathrm{Tf}_{2} \mathrm{~N}_{\mathrm{IL}}{ }^{-} \stackrel{K_{\mathrm{PU} 6}}{\rightleftharpoons} \\
{\left[\mathrm{R}_{3} \mathrm{NH} \cdot \mathrm{PuCl}_{6}\right]_{\mathrm{IL}}{ }^{-}+2 \mathrm{Tf}_{2} \mathrm{~N}_{\mathrm{aq}}{ }^{-} }
\end{aligned}
$$

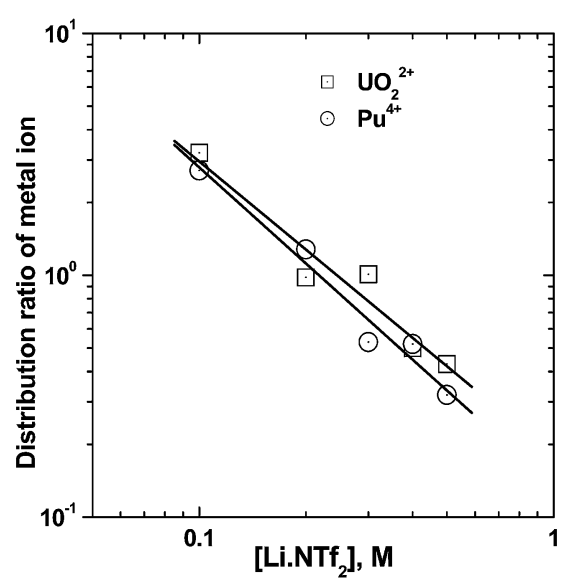

Fig. 8 Distribution ratio of actinide ions by $1 \% \mathrm{v} / \mathrm{v}$ tri- $n$-butyl amine/ $\left[\mathrm{C}_{8} \mathrm{mim}\right]\left[\mathrm{Tf}_{2} \mathrm{~N}\right]$; aqueous phase: $6 \mathrm{M} \mathrm{HCl}$ containing varying concentration of $\mathrm{Li} \cdot \mathrm{NTf}_{2}$ salt; Pu(Iv) slope: $-1.32 \pm 0.13$; U(VI) slope: $-1.21 \pm 0.18$. 


$$
\begin{aligned}
\mathrm{UO}_{2} \mathrm{Cl}_{4 \mathrm{aq}}{ }^{2-}+\mathrm{R}_{3} \mathrm{NH}_{\mathrm{IL}}{ }^{+}+ & 2 \mathrm{Tf}_{2} \mathrm{~N}_{\mathrm{IL}}{ }^{-} \stackrel{K_{\mathrm{U} 4}}{\rightleftharpoons} \\
& {\left[\mathrm{R}_{3} \mathrm{NH} \cdot \mathrm{UO}_{2} \mathrm{Cl}_{4}\right]_{\mathrm{IL}}^{-}+2 \mathrm{Tf}_{2} \mathrm{~N}_{\mathrm{aq}}{ }^{-} }
\end{aligned}
$$

where, $K_{\mathrm{M} x}$ is the conditional extraction constant $(\mathrm{M}=\mathrm{U}$ or $\mathrm{Pu}$; $x=3,4,5,6$ accordingly and indicates the number of chloride ions involved). It should be noted that similar experiments could not be performed in $\mathrm{HNO}_{3}$ medium (unlike those in $\mathrm{HCl}$ medium) due to poor extraction of $\mathrm{UO}_{2}{ }^{2+}$ and $\mathrm{Pu}^{4+}$ in the nitric acid solution.

\subsection{Modeling of actinides extraction data in the presence of amines}

Considering the low $\mathrm{UO}_{2}{ }^{2+}$ and $\mathrm{Pu}^{4+}$ extraction efficiency of the amines in $\mathrm{HNO}_{3}$ medium, we performed data fitting only for the $\mathrm{UO}_{2}{ }^{2+}$ and $\mathrm{Pu}^{4+}$ extraction data recorded for TBA in $\mathrm{HCl}$ medium. A general extraction model has previously been developed $^{35}$ and has proven to very satisfactorily describe liquid-liquid extraction of actinides and other metallic elements towards IL phases. In view of modeling the data of this work, we therefore rely on this model, together with the specific experimental data on $\mathrm{Tf}_{2} \mathrm{~N}^{-}$and $\mathrm{C}_{8} \mathrm{mim}^{+}$solubility in $\mathrm{H}_{2} \mathrm{O} / \mathrm{HCl}$ medium. Details of the mathematical treatment and software procedures can be found elsewhere. ${ }^{34}$ The basic assumptions of the calculations are: (i) successive complexation of actinide with $\mathrm{Cl}^{-}$in the aqueous phase, (ii) extraction may concern any of the possible chlorocomplexes: $\mathrm{UO}_{2}{ }^{2+}$, $\mathrm{UO}_{2} \mathrm{Cl}^{+}, \mathrm{UO}_{2} \mathrm{Cl}_{2},\left[\mathrm{UO}_{2} \mathrm{Cl}_{3}\right]^{-}$and $\left[\mathrm{UO}_{2} \mathrm{Cl}_{4}\right]^{2-}$ for $\mathrm{U}$ and $\mathrm{Pu}^{4+}$, $\mathrm{PuCl}^{3+},\left[\mathrm{PuCl}_{2}\right]^{2+},\left[\mathrm{PuCl}_{3}\right]^{+}, \mathrm{PuCl}_{4},\left[\mathrm{PuCl}_{5}\right]^{-}$and $\left[\mathrm{PuCl}_{6}\right]^{2-}$ for $\mathrm{Pu}$, (iii) extraction of positively charged species proceeds solely by the transfer of $\mathrm{C}_{8} \mathrm{mim}^{+}$to the aqueous phase to compensate the charge, as no $\mathrm{H}^{+}$is present in the IL phase (see above), and extraction of negatively charged species implies transfer of $\mathrm{Tf}_{2} \mathrm{~N}^{-}$anions to comply with the electro-neutrality principle, (iv) metal extraction in the absence of extracting agent simply adds to the extraction in the presence of extracting agent, and (v) the effective ligand concentration is constant, whatever are the chemical conditions. In the calculations, whenever known, the successive complexation constants have been fixed to their published thermodynamical values. ${ }^{36}$ This corresponds to formation of $\mathrm{UO}_{2} \mathrm{Cl}^{+}\left(K_{1}=1.48\right)$ and $\mathrm{UO}_{2} \mathrm{Cl}_{2}\left(K_{2}=0.08\right)$, and also the formation of $\mathrm{PuCl}^{3+}\left(K_{1}=63.1\right)$. The other successive complexation constants are not known, although experiments detailed in section 3.1 clearly demonstrate that negatively charged $\mathrm{U}(\mathrm{vI})$ and $\mathrm{Pu}(\mathrm{IV})$ complexes do exist in the solution and are extracted, even in the absence of amine. Therefore, in the model, the unknown successive complexation constants were included in the overall extraction conditional constants, in order to maintain the number of unknown parameters to a reasonable value.

Another important point of the calculations concerns the increase of $\mathrm{C}_{8} \mathrm{mim}^{+}$solubility as a function of $\mathrm{HCl}$ concentration (ESI $\dagger$ ). This trend is in line with previous data obtained for $\left[\mathrm{C}_{4} \mathrm{mim}\right]\left[\mathrm{Tf}_{2} \mathrm{~N}\right]{ }^{26}$ It is important to point here that these data have been obtained in the absence of metal ( $\mathrm{U}$ or $\mathrm{Pu}$ ) and in the absence of TBA, thus evidencing a primary effect of the $\mathrm{HCl}$ concentration onto the equilibrium concentrations in the aqueous phase. These values cannot be significantly modified owing to the very low metal concentration and were thus considered as equilibrium values in the calculations.

The collected experimental data correspond to three different chemical conditions: (i) $\left[\mathrm{R}_{3} \mathrm{~N}\right]=42 \mathrm{mM}$, variable $\mathrm{HCl}$ concentration, (ii) $[\mathrm{HCl}]=6 \mathrm{M}$, variable $\mathrm{R}_{3} \mathrm{~N}$ concentration, and (iii) $\left[\mathrm{R}_{3} \mathrm{~N}\right]=42 \mathrm{mM},[\mathrm{HCl}]=6 \mathrm{M}$, variable $\operatorname{LiTf}_{2} \mathrm{~N}$ concentration. Adding $\operatorname{LiTf}_{2} \mathrm{~N}$ salt to acidic solutions in such biphasic systems has been shown to lead to a very complex interplay between all ions from the two phases, leading to intricate ion exchanges. ${ }^{25}$ In particular, the IL solubility product is highly dependent on the initial acidity, owing to the solubility of $\mathrm{HTf}_{2} \mathrm{~N}$ in the IL phase. As a consequence, the added amount of $\mathrm{Tf}_{2} \mathrm{~N}^{-}$is not equal to the equilibrium amount of this ion, while the latter, that was not measured, would be needed in the calculation, instead of the former. We thus excluded from the fits the last series of data. Another consequence of this effect is that the slope analysis that has been performed (Fig. 3, 7 and 8) is distorted as compared to reality, in a way that cannot be easily quantified. The slopes thus derived are just indicative of the process at work and do not provide a quantitative basis.

First, various trials have been performed in order to understand and evaluate the contributions of the individual extractions of the species present in the aqueous phase. For both U(vI) and $\mathrm{Pu}(\mathrm{Iv})$ data, assuming extraction of any of the positively charged species leads to a decrease in the $D$ values as a function of $\mathrm{HCl}$, which is in disagreement with the experimental trend. This decrease is mainly due to the large impact of the $\mathrm{C}_{8} \mathrm{mim}^{+}$ values onto the extraction conditional constants but also to the fact that by increasing the $\mathrm{HCl}$ value, positively charged species are eventually transformed into a neutral or negatively charged species and thus, disappear from the speciation. As a consequence, in a second step, we considered only extraction of the neutral and negatively charged species. For each metal, the data $D$ vs. $\mathrm{HCl}$ and $D$ vs. [TBA] have been fitted together. Table 3 gathers the conditional extraction constants, $K_{\mathrm{M} x}$, and the stoichiometric coefficients for the ligand, $p_{\mathrm{M} x}$, corresponding to the dotted lines in Fig. 6 and the fitted lines in Fig. 7. For U(vI), the conditional extraction constant for $\left[\mathrm{UO}_{2} \mathrm{Cl}_{3}\right]^{-}$is lowered to zero whatever its starting values. Imposing extraction of $\left[\mathrm{UO}_{2} \mathrm{Cl}_{4}\right]^{2-}$ alone gives a very good fit (Fig. 6 and 7), with a ligand stoichiometry equal to 1.4 , in excellent agreement with the result derived from the slope analysis (Fig. 7). Allowing extraction of $\mathrm{UO}_{2} \mathrm{Cl}_{2}$ in addition to that of $\left[\mathrm{UO}_{2} \mathrm{Cl}_{4}\right]^{2-}$ does not improve the quality of the fit. It may be noted that the extraction

Table 3 Values of the fitting parameters for $\mathrm{Pu}^{4+} / \mathrm{HCl} / / \mathrm{TBA} /\left[\mathrm{C}_{8} \mathrm{mim}\right]$ $\left[\mathrm{Tf}_{2} \mathrm{~N}\right]$ and $\mathrm{UO}_{2}{ }^{2+} / \mathrm{HCl} / \mathrm{TBA} / \mathrm{C}_{8} \mathrm{mim} \cdot \mathrm{Tf}_{2} \mathrm{~N}$. Values in parenthesis correspond to uncertainties for a $5 \%$ increase in $\chi^{2}$ values

\begin{tabular}{llll}
\hline Metal ion & $K_{\mathrm{M} x}$ & $p_{\mathrm{M} x}$ & $\chi^{2}$ \\
\hline $\mathrm{UO}_{2}{ }^{2+}$ & $3 \times 10^{-5}\left( \pm 1 \times 10^{-5}\right)$ & $4.4( \pm 0.2)$ & 0.025 \\
$\mathrm{Pu}^{4+}$ & $x=4$ & $x=4$ & \\
& $3 \times 10^{-6}\left( \pm 1 \times 10^{-5}\right)$ & $0.8( \pm 0.6)$ & 0.31 \\
& $x=6$ & $x=6$ &
\end{tabular}


of $\left[\mathrm{UO}_{2} \mathrm{Cl}_{4}\right]^{2-}$ was already evidenced in the absence of TBA (section 3.2). Similarly, for $\mathrm{Pu}(\mathrm{vI})$, the conditional extraction constant for $\left[\mathrm{PuCl}_{5}\right]^{-}$is lowered to zero by the fitting procedure whatever the conditions. A very good fit is obtained with extraction of $\left[\mathrm{PuCl}_{6}\right]^{2-}$ alone (Fig. 6 and 7) with a ligand stoichiometry equal to 0.80 . This value is somehow different from that obtained with the slope analysis method but the uncertainty on this value is quite high (see Table 3, where errors on the parameter values are calculated for an increase of $5 \%$ of the $\chi^{2}$ value). This may be ascribed, in part, to the limited number of experimental data points available. Allowing the extraction of $\mathrm{PuCl}_{4}$, in addition to that of $\left[\mathrm{PuCl}_{6}\right]^{2-}$, does not improve the quality of the fit. These modeling results are in line with the general model previously proposed. ${ }^{22}$ In particular, they confirm the role of anion exchange at high acidity, which was not considered in another publication. ${ }^{23}$

\section{Conclusions}

Our results show that in the absence of extracting agent, in both $\mathrm{HCl}$ and $\mathrm{HNO}_{3}$ media, for both $\mathrm{U}(\mathrm{vI})$ and $\mathrm{Pu}(\mathrm{Iv})$, extraction proceeds at high acidic conditions according to an anion exchange mechanism, involving the $\mathrm{NTf}_{2}{ }^{-}$anion of the IL. Although these results are limited in terms of ILs nature and chosen metal, they seem to indicate that anion exchange is unavoidable. Addition of amines does not significantly hampers the anion exchange mechanism, which is still occurring without any significant contribution of neutral species. Again, these results are limited in terms of investigated systems but they indicate that ILs strongly favor charged species rather than neutral ones. Therefore, in order to tackle the problem of pollution of the aqueous phase at high acidities, a possibility would be to use sacrificial anions, in a way similar to the attempts already made with some success with sacrificial cations at low acidities. ${ }^{37}$ Another idea would be to use IL based on low cost anions instead of the $\mathrm{NTf}_{2}{ }^{-}$. For example, trihexyl-(tetradecyl)phosphonium chloride $\left(\mathrm{P}_{66614} \mathrm{Cl}\right)$ is a water-immiscible IL. On a very different perspective, one should try to understand why amines are almost inefficient in $\mathrm{HNO}_{3}$ medium, while they are efficient in $\mathrm{HCl}$. This may be due to partial protonation of the amine in the IL phase, because $\mathrm{HNO}_{3}$ solubilizes in IL phase while $\mathrm{HCl}$ does not. Additional experiments along these lines are under progress in our laboratories.

\section{Acknowledgements}

The authors (SAA and PKM) are thankful to Dr A. Goswami, Head, Radiochemistry Division for his constant encouragement.

\section{References}

1 K. L. Nash, C. Madic, J. N. Mathur and J. Lacquement, Actinide Separation Science and Technology, in Chemistry of the Actinide and Transactinide Elements, ed. L. R. Morss, N. M. Edelstein, J. Fuger and J. J. Kratz, Springer, The Netherlands, 2006, vol. 24, pp. 2622-2796.
2 S. A. Ansari, P. N. Pathak, P. K. Mohapatra and V. K. Manchanda, Sep. Purif. Rev., 2011, 40, 43-76.

3 K. Binnemans, Chem. Rev., 2007, 107, 2592.

4 I. Billard, Ionic liquids: New hopes for efficient lanthanide/ actinide extraction and separation, in Handbook on the Physics and Chemistry of Rare Earths, ed. J. C. G. Bunzli and V. Pecharsky, Elsevier Science Pub, B.V., Amsterdam, 2013.

5 X. Sun, H. Luo and S. Dai, Chem. Rev., 2012, 112, 2100.

6 A. Stojanovic and B. K. Keppler, Sep. Sci. Technol., 2012, 47, 189-203.

7 I. Billard, A. Ouadi, E. Jobin, J. Champion, C. Gaillard and S. Georg, Solvent Extr. Ion Exch., 2011, 29, 577-601.

8 M. L. Dietz and D. C. Stepinski, Talanta, 2008, 75, 598-603. 9 V. A. Cocalia, M. P. Jensen, J. D. Holbrey, S. K. Spear, D. C. Stepinski and R. D. Rogers, Dalton Trans., 2005, 1966-1971.

10 A. E. Visser and R. D. Rogers, J. Solid State Chem., 2003, 171, 109-113.

11 G. A. Pribylova, J. Radioanal. Nucl. Chem., 2011, 288, 693-697.

12 P. K. Mohapatra, P. Kandwal, M. Iqbal, J. Huskens, M. S. Murali and W. Verboom, Dalton Trans., 2013, 43434347.

13 Y. Shen, X. Tan, L. Wang and W. Wu, Sep. Purif. Technol., 2011, 78, 298-302.

14 M. Bonnaffe-Moity, A. Ouadi, V. Mazan, S. Miroshnichenko, D. Ternova, S. Georg, M. Sypula, C. Gaillard and I. Billard, Dalton Trans., 2012, 7526.

15 Y. Zuo, J. Chen and D. Li, Sep. Purif. Technol., 2008, 63, 684690.

16 X. Sun, Y. Ji, F. Hu and D. Li, Talanta, 2010, 81, 1877-1883.

17 A. Rout, K. A. Venkatesan, T. G. Srinivasan and P. R. VasudevaRao, Sep. Purif. Technol., 2012, 95, 26-31.

18 M. Srncik, D. Kogelnig, A. Stojanovic, W. Koerner, R. Krachler and G. Wallner, Appl. Radiat. Isot., 2009, 67, 2146-2149.

19 A. E. Visser, R. P. Swatloski, W. M. Reichert, S. T. Griffin and R. D. Rogers, Ind. Eng. Chem. Res., 2000, 39, 3596-3604.

20 S. Carda-Broch, A. Berthod and D. W. Armstrong, Anal. Bioanal. Chem., 2003, 375, 191-199.

21 H. Heitzman, B. A. Young, D. J. Rausch, P. Rickert, D. C. Stepinski and M. L. Dietz, Talanta, 2006, 69, 527-531.

22 I. Billard, A. Ouadi and C. Gaillard, Dalton Trans., 2013, 6203-6212.

23 C. A. Hawkins, S. L. Garvey and M. L. Dietz, Sep. Purif. Technol., 2012, 89, 31-38.

24 N. Srinivasan, M. N. Nadkarni, G. R. Balasubramanian, R. T. Chitnis and H. R. Siddiqui, Pilot plant for the separation of U-233 at Trombay, BARC Report-643, 1972.

25 V. Mazan, I. Billard and N. Papaiconomou, RSC Adv., 2104, 4, 13371-13384.

26 C. Gaillard, V. Mazan, S. Georg, O. Klimchuk, M. Sypula, I. Billard, R. Schurhammer and G. Wipff, Phys. Chem. Chem. Phys., 2012, 14, 5187-5199.

27 Z. Yoshida, S. G. Johnson, T. Kimura and J. R. Krsul, in The Chemistry of Actinide and Transactinide Elements, ed. L. R. 
Morss, N. M. Edelstein, J. Fuger and J. J. Katz, Spinger, The Netherlands, 1986, vol. 2, p. 714.

28 A. Rout, K. A. Venkatesan, T. G. Srinivasan and P. R. VasudevaRao, Radiochim. Acta, 2010, 98, 459-466.

29 K. V. Lohithakshan and S. K. Aggarwal, Radiochim. Acta, 2008, 96, 93-97.

30 A. Rout, K. A. Venkatesan and T. G. Srinivasan, Sep. Purif. Technol., 2012, 97, 164-171.

31 A. B. Patil, P. Pathak, V. S. Shinde, S. V. Godbole and P. K. Mohapatra, Dalton Trans., 2013, 1519-1529.

32 N. Papaiconomou, G. Vite, N. Goujon, J. M. Leveque and I. Billard, Green Chem., 2012, 14, 2050-2056.
33 A. Sengupta, P. K. Mohapatra, M. Iqbal, J. Huskens and W. Verboom, Dalton Trans., 2012, 6970-6979.

34 A. Ruas, P. Pochon, J. P. Simonin and P. Moisy, Dalton Trans., 2010, 10148.

35 M. Sypula, A. Ouadi, C. Gaillard and I. Billard, RSC Adv., 2013, 3, 10736-10744.

36 R. Guillamont, T. Fanghaenel, V. Neck, J. Fuger, D. A. Palmer, I. Grenthe and M. H. Rand, Update on the chemical thermodynamics of uranium, neptunium, plutonium, americium and technetium, Elsevier, Amsterdam, 2003.

37 H. Luo, S. Dai, P. V. Bonnesen, A. C. Buchanan, J. D. Holbrey, N. J. Bridges and R. D. Rogers, Anal. Chem., 2004, 76, 3078-3083. 